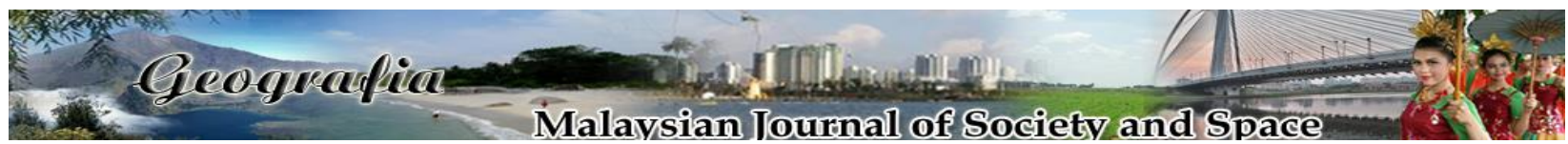

\title{
Integriti akademik dalam kalangan mahasiswa Universiti Kebangsaan Malaysia (UKM)
}

\author{
Nur Hafizah Yusoff \\ Program Antropologi \& Sosiologi, Pusat Pembangunan, Sosial dan Persekitaran, \\ Fakulti Sains Sosial dan Kemanusiaan, Universiti Kebangsaan Malaysia \\ Correspondence: Nur Hafizah Yusoff (email: nur_hafizah@ukm.edu.my)
}

Received: 15 November 2019; Accepted: 22 November 2019; Published: 25 November 2019

\begin{abstract}
Abstrak
Integriti merupakan konsep yang penting terutamanya membentuk sebuah masyarakat yang harmoni. Banyak kajian dilakukan terutamanya di Malaysia yang dilakukan berkaitan dengan isu integriti lebih memfokuskan kepada isu integriti di tempat kerja khususnya dalam kalangan penjawat awam. Walhal, integriti bukan sahaja berkisar tentang sektor pekerjaan semata-mata. Oleh yang demikian, artikel ini akan membincangkan mengenai integriti akademik dalam kalangan mahasiswa. Integriti akademik juga semakin meruncing kini kerana dengan kemudahan teknologi telah memudahkan pelajar untuk mengakses maklumat dan terlibat dalam plagriasm. Seseorang pelajar seharusnya perlu memiliki integriti yang tinggi bagi mencapai kejayaan. Oleh itu kajian ini dilaksanakan untuk mengkaji integriti akademik dalam kalangan pelajar Universiti Kebangsaan Malaysia (UKM), Bangi. Kajian ini bertujuan meneliti tahap pemahaman mahasiswa mengenai konsep integriti secara umum dan tahap integriti akademik dalam kalangan mahasiswa. Kajian ini akan memfokuskan kepada pelajar ijazah sarjana muda yang sedang melanjutkan pelajaran di UKM, Bangi. Data dipersembahkan secara deskriptif frekuansi iaitu melalui frekuensi dan peratusan. Hasil daripada kajian yang telah dilakukan masih terdapat pelajar yang tidak memahami konsep integriti dan terdapat mahasiswa yang terlibat dalam pelanggaran integriti akademik samada secara sedar ataupun tidak. Kesimpulannya, isu integriti akademik dalam kalangan mahasiswa sememangnya ada dan jika tidak dipandang serius dan tidak diatasi, ianya akan membawa kepada potensi untuk mahasiswa ini terlibat dalam pelanggaran integriti di tempat kerja kelak.
\end{abstract}

Kata kunci: integriti, integriti akademik, mahasiswa, plagiarism, sosiologi, tingkah laku devian 


\title{
Academic integrity among National University of Malaysia (UKM) students.
}

\begin{abstract}
Integrity is an important concept especially in shaping a harmonious society. Many research has been done on integrity especially in Malaysia were focused on integrity at work especially among public servants. Nevertheless, integrity is beyond that. Therefore, this article will be focusing on academic integrity among students. Academic integrity is also increasing nowadays as technology has made it easier for students to access information and engage in plagiarism. A student must have high integrity to success in their life. This study was at National University of Malaysia (UKM), Bangi. This study aimed to looking at knowledge of integrity among students and also to examine the level of understanding of academic integrity. Undergraduate students at various faculty in UKM, Bangi were chosen to answer the questionnaire. Data are presented descriptively using frequencies and percentage. The main findings are, there are still students who do not understand the concept of integrity. Besides that, there are numbers of students has been involved in the violation of academic integrity. In conclusion, the issue of academic integrity among students is already exists and if it is not taken seriously and it will lead to the potential for this student to be involved in breach of integrity in the future (workplace and daily life).
\end{abstract}

Keywords: integrity, academic integrity, university students, plagiarism, sociology, deviant behavior

\section{Pengenalan}

Integriti bukan isu yang baru dibincangkan di dalam dunia pekerjaan mahupun akademik. Integriti adalah salah satu isu yang banyak dibincangkan di dalam dunia akademik. Oleh itu, secara umumnya integriti amat penting bagi memastikan individu menjalankan tanggungjawab secara jujur dan amanah (Wayandiana Abdullah \& Rahimah Abdul Aziz, 2019). Memiliki sikap yang jujur, bertanggungjawab, amanah, ikhlas dan telus dalam membuat kerja adalah penting di dalam diri seorang manusia. Hal ini kerana, nilai-nilai ini boleh membantu untuk membina dan membentuk integriti seorang manusia. Seterusnya, nilai-nilai ini dapat membantu manusia daripada melakukan kesilapan dan kesalahan (Lowe, Cordery \& Morrison, 2004). Dengan kata lain integriti dan etika dalam melibatkan tindakan baik yang dilakukan dalam kehidupan harian dan mempunyai kaitan erat dengan ajaran agama dan tanggungjawab sebagai manusia (Megat Ayob \& Abd Halim, 2016).

Mahasiswa sering sekali dicanang sebagai bakal pemimpin dan juga kepada pengganti kepada generasi seterusnya. Mahasiswa merupakan aset yang penting bagi membina sebuah negara yang maju dan berdaya saing. Oleh itu, mahasiswa seharusnya memiliki bukan sahaja nilai akademiknya tetapi juga nilai integriti yang tinggi sebelum melangkah ke peringkat yang seterusnya iaitu pekerjaan. Jikalau, sistem integriti dan moral mahasiswa tidak dijaga dengan baik ia boleh memberikan kesan negatif bukan sahaja kepada mahasiswa tetapi juga kepada sistem di dalam sesebuah negara (Ramlan Mustapha, 2016). Kebanyakan manusia gagal melihat impak dan kepentingan nilai moral dan integriti seseorang manusia di dalam membentuk sebuah 
masyarakat yang telus.

Kajian yang telah dibuat oleh Institut Integriti Malaysia pada tahun 2017 terhadap pelajar mahasiswa melibatkan tiga buah universiti awam di Malaysia menunjukkan bahawa 35.8\% mahasiswa menganggap bahawa penerimaan hadiah dalam bentuk wang, barangan atau perkhidmatan yang diberikan adalah bukan rasuah (Anis Yusal Yusoff \& Zarina Mohamad Amin, 2017). Kekurangan pengetahuan mengenai konsep dan nilai integriti di dalam diri seorang pelajar boleh memberikan kesan kepada pekerjaannya pada suatu hari nanti. Selain daripada itu, kes seperti menipu, pemalsuan sijil dan juga plagiarisme boleh menyebabkan kepada kes yang lebih besar seperti rasuah, penyalahgunaan kuasa dan ketidakjujuran di dalam membuat kerja.

\section{Kajian literatur}

\section{Integriti dan amalan rasuah}

Banyak kajian dijalankan berkaitan dengan amalan integriti khususnya di dalam sektor pekerjaan seperti sektor awam. Melalui kajian Nik, Azmi Awang \& Azmi (2012), prestasi dan integriti penjawat perkhidmatan awam di Malaysia masih berada di tahap bermasalah. Laporan Indeks Persepsi Rasuah Antarabangsa (CPI) sekitar 1995-2010 menyaksikan Malaysia tersenarai dalam senarai negara yang mempunyai kadar rasuah yang tinggi, iaitu Malaysia berada di tangga ke 22 pada tahun 1995. Kedudukan Malaysia jatuh ke tangga 37 pada tahun 2003 dan berada di tangga ke 56 bagi tahun 2010 (International Transparency, 1995-2010).

Dalam tempoh berkenaan, skor purata Indeks CPI Malaysia telah ketara menurun dari 5.28 mata pada tahun 1995 kepada 4.4 mata pada tahun 2010. Situasi ini menjelaskan bahawa masalah rasuah dan pengendalian rasuah kian meruncing. Beberapa kajian seperti hasil kajian yang dilakukan oleh Ernst dan Young International pada tahun 1996 mendapati 78 peratus keskes penipuan di dalam agensi kerajaan melibatkan pegawai di dalam jabatan itu sendiri, bukannya pihak luar. Dapatan ini konsisten dengan hasil Laporan Kerajaan Persekutuan pada tahun 2005 yang menunjukkan bahawa penjawat awam sendiri terlibat dalam pelbagai kes salah laku ketika berada di dalam perkhidmatan. Antara kesalahan yang sering dilakukan adalah tidak hadir bekerja (61.4\%), melanggar disiplin (13.1\%), penyalahgunaan dadah $(2.3 \%)$, menerima rasuahh $(2.3 \%)$, masalah hutang yang serius $(0.3 \%)$ dan memiliki harta benda yang diluar kemampuan $(0.1 \%)$.

Rasuah juga turut berlaku dalam urusan pentadbiran tanah (Noraida Harun, 2017). Aspek peluang untuk menerima rasuah, lemahnya sahsiah peribadi dan kurangnya penghayatan nilainilai murni, karenah biroksi dalam hal ehwal tanah menyebabkan ada segelintir individu cuba menyogok pegawai berkhidmat untuk mempercepat urusan hal ehwal tanah dan kelemahan sistem perlaksanaan dan peraturan tempat kerja menjadi antara penyebab berlakunya rasuah dalam urusan pentadbiran tanah.

\section{Integriti dan mahasiswa}

Setiap warga Malaysia merupakan modal insan yang perlu dijaga bagi memastikan pembangunan negara dapat dilaksana. Modal insan sangat penting terutamanya meningkatkan produktiviti dan daya saing sedia ada. Bagi melahirkan modal insan yang berjaya, sistem pendidikan memainkan peranan yang utama. Melalui sistem pendidikan yang holistik, modal 
insan yang seimbang rohani serta jasmani akan berjaya dilahirkan. Justeru itu, adalah menjadi tanggungjawab institusi pendidikan menekankan bukan sahaja aspek pendidikan tetapi aspek nilai-nilai murni berjaya dikuasai oleh para pelajar ketika mereka berada dunia pendidikan. Jika penekanan terhadap nila-nilai murni dan disiplin tinggi berjaya diterapkan, tidak kira apa jua masalah dan cabaran, modal insan ini masih akan kekal patuh kepada nilai, norma dan undangundang. Semestinya, mereka tidak akan mudah terpengaruh dengan anasir-anasir luar untuk melanggar nilai dan etika yang dipegang. (Emilly anak Sakai \& Mohd Dahlan, 2014).

Kajian yang dijalankan oleh Emilly Anak Sakai \& Mohd Dahlan (2014) lebih terarah kepada nilai-nilai yang terdapat dalam diri belia (mahasiswa Universiti Malaysia Sabah UMS). Antara nilai-nilai yang diberi penekanan ialah, nilai kuasa, pencapaian, stimulasi, halatuju diri, keakuran dan keselamatan disimpulkan memmpunyai hubungan signifikan dengan aspek kesejahteraan manusia. Sementara itu, hanya nilai hedonism tidak mmepunyai hubungan langsung dengan aspek kesejahteraan manusia. Beliau turut menyatakan bahwa terdapat perbezaan yang signifikan antara pelajar lelaki dan pelajar wanita dari segi kesejahteraan.

Hasil keputusan bagi antara nilai yang paling penting di antara pelajar lelaki dan perempuan ialah nilai kuasa, hedonisme, stimulasi, kemurahan hati, tradisi dan keakuran. Hasil analisis mendapat bahawa pelajar lelaki lebih mementingkan nilai kuasa, hedonisme dan stimulasi dan kurang dalam nilai keakuran, tradisi dan kemurahan hati. Berbeza dengan pelajarwanita yang lebih mementingkan akan nilai anilai keakuran, adat dan tradisi serta nilai kemurahan hati. Situasi ini jelas menunjukkan bahawa pelajar perempuan lebih matang berbanding pelajar lelaki. Pelajar perempuan bukan sahaja memikirkan akan diri mereka, tetapi juga diri orang lain di persekitaran mereka berbanding pelajar lelaki yang lebih cenderung untuk mendahulukan kepentingan diri mereka. (Emilly Anak Sakai \& Mohd Dahlan, 2014). Dapat disimpulkan bahawa pelajar lelaki lebih berminat untuk mkit sebanyak mempengaruhi mereka untuk bertingkah laku sedemikian. Selain itu, mereka turut akan berasa bangga dan beranggapan mereka sudah dewasa apabila mereka memiliki nilai-nilai berkenaan.

Dapatan tersebut seiring dengan hasil kajian yang pernah dijalankan oleh Muhamad Fadhil (2003), kesejahteraan hidup bertujuan meningkatkan kualiti hidup seseorang dan mengeluarkan mereka dari belenggu masalah. Justeru itu, hidup dalam situasi sihat, selamat, selesa dan aman baik dari segi psikologi atau fizikal menjadi tunjang utama kepada kesejahteraan hidup. Namun demikian, bagi mencapai kualiti hidup yang baik, prosesnya turut perlu berlaku dalam keadaan yang baik. Sebagai contoh, untuk mencapai keselesaan hidup setiap orang itu perlu bekerja keras, bagi mendapatkan pendapatan yang baik. Tiada guna kualiti hidup adalah selesa tetapi mendapatkannya melalui jalan yang salah seperti rasuah dan pecah amanah. Asmah Ahmad (2005) turut mengutarakan pendapat beliau bahawa terdapat kaitan erat antara kualiti hidup dan kesejahteraan hidup. Hal ini kerana, kedua-duanya ibarat magnet saling menarik antara satu sama lain. Jika tiadanya integriti baik dalam diri seseorang magnet tersebut dapat menarik seseorang itu ke jalan yang gelap. Pihak Institut Integriti Malaysia (IIM) telah melakukan satu survei ringkas dalam kalangan mahasiswa. Antara mahasiswa yang terlibat adalah mahasiswa daripada Universiti Kembangsaan Malaysia (UKM), Universiti Sains Malaysia (USM) dan Universiti Teknologi Mara (UiTM). Survei tersebut telah dilakukan pada tahun 2017. Kajian dilakukan bagi mengetahui persepsi mahasiswa terhadap rasuah di Malaysia. Antara dapatan kajian yang diperoleh adalah, sebanyak $35.8 \%$ responden menyatakan menerima wang atau hadiah sebagai balasan atas khidmat yang diberikan bukanlah merupakan satu kesalahan rasuah. Manakala $37.3 \%$ responden turut menyatakan bahawa membuat tuntutan penginapan tugasan luar meskipun penginapan telah disediakan oleh pengajur turut tidak merupakan sebagai satu 
kesalahan (Anis Yusal Yusoff \& Zarina Mohamad Amin, 2017).

Kajian berkaitan mahasiswa dan integriti akademik turut pernah dilakukan di dalam mahupun di luar negara. Ketidakjujuran akademik atau 'academic dishonesty' menjadi cabaran kepada kebanyakan institusi akademik seluruh dunia (Jurdi, Hage \& Chow, 2011). Jones (2011) mendapati majoriti mahasiswa terlibat dalam ketidakjujuran akademik disebabkan oleh beberapa faktor, misalnya $92 \%$ mahasiswa melakukannya disebabkan ingin memperoleh gred yang tinggi dan 75\% melakukannya dengan alasan terlalu sibuk dengan pelajaran dan tugasan. Di New Zealand, sembilan daripada sepuluh pelajar terlibat dalam ketidakjujuran akademik (Williams \& Williams, 2012). Pada tahun 2005, McCabe telah melakukan kajian impak yang sangat signifikan yang merangkumi 80,000 mahasiswa. Hasil dapatan kajian beliau menunjukkan dalam tahun tersebut sebanyak $21 \%$ mahasiswa melakukan ketidakjujuran akademik yang serius sekurangnya sekali. Sebanyak $68 \%$ membuat pengakuan melakukan tugasan secara bersama dan 63\% melakukan plagiat (McCabe, 2005). Harding, Carpenter, dan Finelli (2004) mendapati 28\% mahasiswa mengaku melakukan ketidakjujuran akademik ketika peperiksaan, manakala Josien dan Broderick (2013) dalam kajian mereka menyatakan bahawa 70\% daripada 50,000 pelajar ijazah sarjana muda dalam lingkungan tahun 2002 hingga 2005 pernah meniru dan melakukan ketidakjujuran akademik dan data ini dikumpul daripada 60 kampus diseluruh dunia.

Negara-negara Asia juga tidak terkecuali, apabila kajian Lin dan Wen (2007) di Taiwan menunjukkan peratusan masalah ketidakjujuran akdemik berada pada tahap $61.7 \%$. Galloway (2012) dalam kajiannya terhadap 4316 mahasiswa pengajian tinggi melaporkan hampir 93\% peratus mahasiswa pernah melakukan ketidakjujuran akademik sekurang-kurang sekali dalam pengajian mereka.Diekhoff, LeBeff, Shinohara dan Yushukawa (2009) menyatakan bahawa 55.4\% pelajar di Jepun menipu dalam peperiksaan mereka, manakala Williams, Nathanson \& Paulhus (2010) mendapati bahawa sebanyak 10\% pelajar menyalin secara "cut and paste" daripada sumber internet manakala sebanyak $40 \%$ pelajar menggunakan kaedah yang sama dalam menyelesaikan kertas projek mereka pada tahun sebelumnya.

Dalam konteks Malaysia, kajian akademik berkaitan isu integriti mahasiswa dalam pembelajaran masih kurang dijalankan. Kajian Nurshiha dan Nurliyana (2013) mendapati bahawa 82\% mahasiswa UiTM pernah melakukan ketidakjujuran akademik. Pelajar fakulti teknologi maklumat lebih banyak melakukan ketidakjujuran akademik berbanding fakulti lain, menunjukkan bahawa kemudahan akses kepada ICT dan kemahiran penggunaannya memudahkan lagi aktiviti ketidakjujuran akademik (Mahmoud, Mohammad Javad \& Yusof, 2013). Ramlan Mustapha telah menjalankan kajian dalam kalangan pelajar Muslim di Institut Perguruan pada tahun 2016, beliau mendapati min bagi persepsi mahasiswa Muslim berkaitan isu ketidakjujuran akademik berada pada tahap yang sederhana (2.33). Kesalahan seperti mengubahsuai hasil kerja pelajar lain dan memalsukan senarai rujukan masing-masing memiliki skor min yang sederhana iaitu 2.16. Sebanyak $45 \%$ sahaja mahasiswa mengaku tidak melakukan ketidakjujuran akademik pada tahun 2014 manakala 37\% pada tahun 2015; namun selebihnya mahasiswa membuat pengakuan pernah melakukan ketidakjujuran akademik. Lebih mengejutkan, dapatan menujukkan pelatih membuat pengakuan melakukan ketidakjujuran sekali sekala iaitu sebanyak 29\% daripada mereka dan 3.1\% daripada mereka mengaku membua tketidakjujuran banyak kali; selebihnya melakukan sekurang-kurangnya sekali. Nisbah ini memberikan gambaran bahawa aktiviti ini agak membimbangkan kerana besar kemungkinan akan berterusan jika tidak dibendung (Ramlan Mustapha, 2016). 


\section{Kaedah kajian}

Kajian ini menggunakan pendekatan kuantitatif. Survei menggunakan borang soal selidik akan digunakan bagi mendapatkan data yang dikhendaki. Soalan dalam soal selidik akan merangkumi bahagian sosiodemografi responden (bahagian A), soalan berkaitan pemahaman responden tentang konsep integriti (bahagian B) dan soalan berkaitan integriti responden dalam dunia akademik (bahagian C). Soalan Bahagian B dan C terdiri daripada soalan berbentuk skala likert. Pengkaji telah memilih pelajar melalui kaedah persampelan 'convenience sampling'. Sampel kajian terdiri daripada pelajar prasiswazah di UKM, Bangi. Seramai 200 orang responden yang memberikan kerjasama menjawab soal selidik yang diedarkan. Pengedaran soal selidik mengambil masa selama tiga minggu. Setelah borang soal selidik selesai dijawab, pengkaji memulakan memproses dan menganalisis data menggunakan perisian Statistical Package for Social Science (SPSS). Persembahan data dilakukan secara statistik deskriptif iaitu, data dipersembahkan secara frekuensi, peratusan dan min.

\section{Hasil kajian dan perbincangan}

\section{Sosiodemografi}

Dapatan kajian bagi sosio demografi responden di dalam kajian rintis ini merangkumi aspekaspek seperti umur, jantina, bangsa, fakulti, tahun pengajian dan negeri. Jumlah responden di dalam kajian rintis ini adalah sebanyak 200 orang responden yang terdiri daripada pelajar ijazah sarjana muda Universiti Kebangsaan Malaysia (UKM), Bangi pelbagai fakulti. Jumlah responden lelaki adalah sebanyak $40.6 \%$ orang manakala jumlah responden perempuan adalah sebanyak $59.4 \%$ peratus. Seterusnya taburan umur responden di dalam kajian ini adalah lingkungan dari umur 20 tahun sehingga 24 tahun. Kebanyakan responden berumur 21 tahun dan terdapat juga responden yang berumur 24 tahun.

Taburan responden mengikut fakulti dan tahun pengajian pula menunjukkan kebanyakan responden adalah pelajar tahun tiga iaitu sebanyak 122 orang responden manakala pelajar tahun dua adalah sebanyak 35 orang responden dan selebihnya seramai 43 orang adalah pelajar tahun pertama. Berdasarkan fakulti-fakulti yang terdapat di UKM, taburan responden adalah dari Fakulti Ekonomi Pengurusan (FEP) iaitu sebanyak 12\% orang responden, diikuti dengan Fakulti Sains dan Teknologi (FST) sebanyak sembilan peratus. Manakala Fakulti Pendidikan sebanyak 21\% peratus dan Fakulti Sains Sosial dan Kemanusiaan (FSSK) sebanyak 47\% orang responden. Seterusnya Fakulti Undang-Undang (FUU) sebanyak sembilan peratus responden dan pelajar dari Fakulti Pengajian Islam (FPI) sebanyak dua peratus responden.

\section{Sumber pengetahuan tentang integriti}

Respons yang diberikan oleh responden mengenai konsep integriti adalah sebanyak 95.7\% responden mengakui mengetahui akan konsep integriti manakala responden selebihnya tidak mengetahui mengenai konsep integriti. 
Jadual 1. Sumber pengetahuan

\begin{tabular}{lcc}
\hline \multicolumn{1}{c}{ Sumber pengetahuan } & Bilangan $(\mathbf{N})$ & Peratus (\%) \\
\hline Keluarga & 85 & 42.5 \\
Kawan & 50 & 25.0 \\
Sekolah & 178 & 89.0 \\
Internet & 122 & 61.0 \\
Televisyen & 79 & 39.5 \\
Suratkhabar & 108 & 54.0 \\
Lain-lain & 63 & 31.5 \\
& & \\
\hline
\end{tabular}

*responden memilih lebih dari satu jawapan

Jadual 1 menunjukkan sumber pengetahuan responden mengenai konsep integriti. Terdapat pelbagai kaedah dan perantara yang membantu memberikan pengetahuan terhadap responden mengenai konsep integriti secara umum. Kebanyakan responden menyatakan sekolah sebagai sumber yang menyalurkan maklumat berkenaan pengetahuan dan konsep integriti terhadap mereka (89.0\%). Kebanyakan responden turut memperoleh pengetahuan mengenai konsep integriti melalui medium internet iaitu sebanyak $61.0 \%$. Manakala, televisyen turut menyumbang sebanyak $39.5 \%$ pengetahuan terhadap diri responden. Seramai $54.0 \%$ responden pula menyatakan bahawa surat khabar turut menjadi medium untuk mereka mendapatkan maklumat tentang integriti. Sebanyak $25.0 \%$ responden menyatakan perbualan bersama rakan-rakan turut membantu mereka mengetahui mengenai integriti. Manakala, seramai $42.5 \%$ responden juga menyatakan bahawa mereka mendapatkan pengetahuan mengenai konsep integriti melalui keluarga mereka sendiri. Jika dilihat daripada pecahan jawapan yang diberikan oleh responden, dapat disimpulkan bahawa agen sosialisasi primer iaitu keluarga memberikan pengetahuan mengenai konsep integriti. Namun demikian, responden turut mendapat pengetahun mengenai integriti daripada pelbagai agen sosialisasi sekunder yang lain.

\section{Integriti akademik}

Integriti akademik adalah sebarang perlakuan yang melanggar peraturan yang berkaitan di dalam dunia akademik, samada ianya dilakukan oleh diri sendiri, pihak ketiga atau terhadap orang lain (Macfarlane, Zhang \& Pun, 2014). Antara perlakuan yang sering berlaku dalam dunia akademik adalah, plagiarism, ghost writing, meniru di dalam peperiksaan, membeli ijazah, memberi rasuah kepada pensyarah dan lain lain (John, Loewenstein \& Rick, 2014). Akademik integriti jika dilakukan ianya bukan sahaja membawa masalah kepada pelajar, bahkan memburukkan nama dan reputasi institusi pendidikan amnya (Lang, 2013).

Kewujudan internet membawa bukan sahaja kebaikan kepada manusia, tetapi turut memberikan impak negatif kepada penggunanya. Internet bertujuan untuk memudahkan urusan seharian, samada untuk berkomunikasi mahupun memudahkan urusan dalam dunia pekerjaan dan pendidikan. Kemudahan internet dan kelajuan servis internet turut menyumbang kepada berlakunya plagiarism dalam kalangan pelajar khususnya (Hu \& Lei, 2012). Plagiarism adalah perbuatan yang dianggap salah dan melanggar etika bahkan undang-undang kerana seseorang itu mencuri idea atau hasil kerja orang lain tanpa memberikan 'kredit' atau penghargaan terhadap penulis asal (Pecorari \& Petric, 2014).

Berdasarkan Jadual 2, boleh disimpulkan bahawa rata-rata responden masih tidak faham mengenai plagiarism. Misalnya, jumlah peratusan sebanyak $38.6 \%$ responden menyatakan 
jawapan yang positif iaitu samada bersetuju dan sangat bahawa tidak membuat rujukan dengan betul adalah satu kesalahan yang dikecualikan. Manakala sebanyak $27.9 \%$ peratus turut bersetuju jika mengambil bahan dari internet, bahan tersebut tidak memerlukan rujukan. Jawapan responden yang bersetuju dan sangat bersetuju dengan penyataan tersebut agak membimbangkan. Hal ini kerana, dalam dunia akademik, rujukan adalah sangat penting. Rujukan yang betul perlu dilakukan kerana penghargaan yang betul perlu diberika kepada orang yang betul. Sumber internet sememangnya menjadi trend pelajar masa kini. Mudah, cepat dan percuma antara sebab mengapa pelajar lebih gemar memilih bahan dari internet (Heckler \& Forde, 2015) berbanding bahan 'hardcopy' untuk melengkapkan tugasan akademik mereka. Namun demikian, tidak memberikan penghargaan atau menulis rujukan adalah satu kesalahan yang besar.

Jadual 2. Plagiarism

\begin{tabular}{lcc}
\hline \multicolumn{1}{c}{ Plagarism } & $\begin{array}{c}\text { Positif (Setuju \& sangat } \\
\text { setuju \%) }\end{array}$ & $\begin{array}{c}\text { Negatif (Tidak setuju, } \\
\text { sangat tidak setuju, tidak } \\
\text { pasti \%) }\end{array}$ \\
\hline $\begin{array}{l}\text { Ambil idea tanpa rujukan yang tepat adalah } \\
\text { plagiarisme }\end{array}$ & 88.2 & 11.8 \\
$\begin{array}{l}\text { Tidak membuat rujukan dengan betul adalah } \\
\text { kesalahan yang dikecualikan }\end{array}$ & 38.6 & 61.4 \\
$\begin{array}{l}\text { Mengambil bahan dari Internet tidak memerlukan } \\
\text { rujukan }\end{array}$ & 27.9 & 72.1 \\
$\begin{array}{l}\text { Pengiktirafan perlu diberikan kepada pengarang } \\
\text { asal }\end{array}$ & 89.3 & 10.7 \\
$\begin{array}{l}\text { Tidak buat rujukan bagi gambar, graf, angka dan } \\
\text { carta adalah kesalahan kecil }\end{array}$ & 49.4 & 50.6 \\
\hline
\end{tabular}

Sebanyak 49.4\% responden memberikan jawapan positif bagi penyataan mengambil rajah, graf, gambar dan carta tetapi tidak meletakkan rujukan adalah satu kesalahan yang kecil bagi responden. Rajah, carta, gambar dan graf lazimnya terhasil selepas para penulis membaca pelbagai bahan bacaan dan melakukan kajian (Sureda, Comas \& Oliver, 2015). Justeru itu, jika mengambil bahan tersebut tanpa adanya sumber rujukan ianya adalah satu kesalahan yang besar. Boleh dikatakan seolah-olah mencuri hasil kerja seseorang secara percuma. Para responden kebanyakannya bersetuju (88.2\%) mengenai penyataan bahawa pengktirafan perlu diberikan kepada pengarang asal. Sebanyak $11.8 \%$ responden yang tidak pasti dan tidak bersetuju dengan penyataan terbabit. Harus diingatkan bahawa, idea pengarang asal yang dipinjam, walau telah diubah ayatnya oleh penulis tetap perlu diberikan penghargaan dan rujukan. Hal ini kerana idea asal tersebut datangnya daripada pengarang asal. Jika tiadanya 'source documentation' dan 'pharaprasing' plagiarism semestinya berlaku (Park, 2003).

Selain daripada plagiarism, pelajar juga sinonim dengan perbuatan penipuan academic (academic cheating). Terdapat kajian lepas yang menyatakan bahawa kejadian menipu di dalam akademik terjadi disebabkan oleh tekanan yang dihadapi oleh para pelajar. Tekanan tersebut datang daripada ibu bapa, rakan-rakan, para pendidik (Sarita, 2015). Selain itu, persekitaran pendidikan yakni sekolah, kolej mahupun universiti dan 'academic anxiety' (Wilkonsin, 2009) turut menyumbang kepada kejadian penipuan akademik dalam kalangan pelajar. 
Berdasarkan Jadual 3, respon yang diberikan oleh para responden adalah menjurus kepada jawapan yang positif. Rata-rata responden menyedari bahawa perbuatan menipu dalam dunia akademik adalah satu perbuatan yang salah. Hanya segelintir responden sahaja yang masih tidak mengetahui akan perbuatan menipu adalah tidak dibenarkan. Sebanyak $58.6 \%$ responden menyatakan bahawa mereka bersetuju dengan penyataan bahawa meniru kawan bukan merupakan satu kesalahan. Perbuatan meniru tugasan akademik umpamanya antara perbuatan yang sering dilakukan oleh para pelajar tidak kira di sekolah mahupun universiti (Friedman, Blau \& Eshet-Alkalai, 2016). Selain itu, peratusan sebanyak $46.6 \%$ dicatatkan bagi penyataan bahawa menandatagani bagi pihak kawan yang tidak datang ke kuliah adalah dibenarkan. Perbuatan tersebut adalah salah kerana ianya menipu pensyarah dan lazimnya lebih mudah dilakukan jika kelas tersebut mempunyai bilangan pelajar yang ramai sehingga menyukarkan pensyarah untuk mengenalpasti para pelajarnya. Bagi mengelakkan kesalahan tersebut berlaku atau berulang, pensyarah boleh menyebut nama para pelajar sendiri dan tidak mengedarkan borang kedatangan untuk para pelajar tandatagani.

Jadual 3. Cheating

\begin{tabular}{lcc}
\hline \multicolumn{1}{c}{ Cheating } & $\begin{array}{c}\text { Positif (Setuju \& sangat } \\
\text { setuju \%) }\end{array}$ & $\begin{array}{c}\text { Negatif (Tidak setuju, } \\
\text { sangat tidak setuju, tidak } \\
\text { pasti \%) }\end{array}$ \\
\hline Meniru kawan bukan satu kesalahan & 58.6 & 41.4 \\
Tandatangan bagi pihak kawan yang tidak datang & 46.6 & 53.4 \\
kuliah/tutorial & 22.7 & 77.3 \\
Upah orang lain menyiapkan tugasan dibenarkan & 2.2 & 97.8 \\
Membawa nota ketika peperiksaan dibenarkan & & \\
\hline
\end{tabular}

Manakala, sebanyak $77.3 \%$ reseponden menyatakan bahawa mengupah orang lain untuk menyiapkan tugasan adalah tidak dibenarkan. Selebihnya terdapat segelintir responden yang beranggapan bahawa perbuatan mengupah pihak ketiga menyiapkan tugasan akademik mereka bukan merupakan suatu kesalahan. Jika responden melakukan perkara terbabit bermakna mereka tidak bertanggungjawab terhadap diri mereka sendiri. Perbuatan ini seolah-olah menyatakan bahawa ilmu pengetahuan itu adalah perkara remeh yang boleh dilaksanakan secara jual-beli. Institusi akademik kini turut menjadi perniagaan bagi segelintir individu. Terdapat individu yang menyediakan perkhidmatan menyiapkan tugasan, latihan ilmiah dan tesis dengan bayaran yang lumayan. Situasi ini menunjukkan bahawa permintaan yang ada daripada pelajar menyebabkan, ghostwriting ini berleluasa (Mitchell, 2008).

Manakala, hanya sebanyak $2.2 \%$ responden menyatakan bahawa membawa nota semasa peperiksaan berlangsung adalah tidak menjadi satu kesalahan. Pendapat ini adalah tidak benar sama sekali, rata-rata institusi pengajian tinggi mempunyai garis panduan yang melarang para pelajar membawa nota ke dalam dewan peperiksaan. Jika ditangkap, pelajar tersebut bakal dikenakan tindakan iaitu digagalkan subjek berkenaan, dibicarakan dan didenda. Lain pula halnya, jika peperiksaan tersebut berkonsepkan 'open book exam', maka para pelajar dibenarkan untuk membawa buku dan nota bagi menjawab soalan peperiksaan berkenaan (Ioannidou, 1997). Selain itu para responden turut ditanya mengenai pendapat mereka samada membeli sijil pelajaran adalah dibolehkan. Respon yang diberikan oleh responden adalah, 95.3 peratus responden menyatakan bahawa perbuatan tersebut adalah salah dan tidak patut dilakukan. Kini, terdapat banyak organisasi yang menawarkan sijil secara pantas, tanpa perlu menghadiri kuliah, menjawab peperiksaan hanya perlu mengeluarkan wang untuk tujuan tersebut. Di Malaysia juga 
banyak kes dilaporkan terutamanya membabitkan pembelian sijil ijazah Doktor Falsafah (PhD). Perbuatan membeli sijil palsu adalah sangat tidak beretika (Johnson, 2006) dan seolah-olah memandang rendah institusi pendidikan itu sendiri. Ijazah Doktor Falsafah misalnya, adalah ijazah tertinggi di dalam institusi pendidikan dan untuk memilikinya seseorang pelajar itu perlu mempunyai ilmu akademik yang tinggi dan mampu mengaplikasi semua ilmu akademik melalui penulisan tesis. Selanjutnya, perlu mempertahankan tesis tersebut melalui peperiksaan lisan (viva voce). Sekiranya lulus, baru pelajar tersebut akan dianugerahkan sijil $\mathrm{PhD}$ yang membawa gelaran 'Dr'. Oleh yang demikian, adalah sangat tidak adil bagi pelajar yang bertungkus lumus menyiapkan pengajian $\mathrm{PhD}$ mereka demi mendapatkan gelaran 'Dr' sedangkan ada di luar sana individu yang membayar sejumlah wang bagi mendapatkan ijazah $\mathrm{PhD}$ dengan mudah dan pantas.

\section{Kesimpulan}

Integriti adalah satu konsep yang perlu diketahui, dipegang, dihayati dan dilaksanakan oleh setiap orang. Sukar untuk kita mengawal integriti diri orang lain, berbanding mengawal integriti diri sendiri. Justeru itu, setiap orang perlu memastikan bahawa integriti diri sentiasa berada di dalam kawalan agar tidak mudah terpengaruh dengan anasir-anasir luar yang cuba untuk menjatuhkan integriti diri yang dipegang. Dalam dunia akademik, integriti akademik sama pentingnya dengan integriti di tempat kerja. Institusi akademik bertanggungjawab menyediakan para pelajar dengan ilmu dan nilai integriti yang tinggi bagi mempersiapkan mereka sebelum melangkah ke dunia kerja. Jika gagal berbuat demikian, maka tidak mustahil para pelajar yang dahulunya biasa melanggar integriti akademik akan terjerumus dengan kesalahan integriti yang lebih serius di dunia kerja kelak. Institusi akademik adalah tempat untuk para pelajar menimba ilmu daripada para pensyarah yang berkaliber. Namun demikian, tidak semua pelajar menekankan kepada aspek integriti akademik sepanjang tiga atau empat tahu mereka di universiti. Pelajar adakalanya, cenderung untuk melawan nilai dan norma demi untuk memenuhi keperluan dan kehendak mereka. Justeru itu, tidak hairanlah jika terdapat para pelajar yang mengamalkan plagiarism, menipu semasa menyiapkan tugasan, menipu ketika menjawab peperiksaan dan menggunakan rakan-rakan untuk kepentingan akademik mereka. Isu akademik integriti ini jika tidak ditagani secara serius, ianya akan memberi imej negatif kepada institusi pendidikan secara umumnya. Langkah pencegahan dan pemantauan yang proaktif perlu dilakukan oleh semua pihak berkepentingan terutamanya pihak institusi pendidikan itu sendiri bagi memastikan para pelajar mematuhi segala peraturan akademik yang diperuntukkan. Selain itu, pendidikan dan pemerkasaan mengenai nilai integriti akademik perlu diperluaskan bagi memastikan para pelajar sentiasa peka dengan tingkah laku yang melanggar integriti ketika berada di universiti.

\section{Penghargaan}

Terima kasih kepada geran penyelidikan GGPM-2018-073 yang membantu pelaksanaan kajian dan membiayai penerbitan artikel ini. 


\section{Rujukan}

Anis Yusal Yusoff \& Zarina Mohamad Amin. (2017). Laporan hasil kajian persepsi mahasiswa mengenai rasuah di Malaysia. Institut Integriti Malaysia.

Asmah Ahmad. 2005. Kualiti hidup dan pengurusan persekitaran di Malaysia. Prosiding Seminar Kebangsaan Pengurusan Persekitaran (2005). Bangi: Program Pengurusan Persekitaran, Pusat Pengajian Siswazah UKM.

Diekhoff, G.M., LaBeff, E.E., Shinohara, K., \& Ysukawa. K. (2009). College cheating in Japan and the United States. Research in Higher Education, 40(3), 343-353.

Emilly Anak Sakai \& Mohd Dahlan A. Malek. (2014). Konsep integriti dan nilai murni terhadap kesejahteraan hidup dalam kalangan pelajar universiti yang tinggal di bandar dan luar bandar: Satu kajian di Universiti Malaysia Sabah. Seminar Kebangsaan Integriti Keluarga 2014. Prosiding.

Friedman, A., Blau, I., \& Eshet-Alkalai, Y. (2016). Cheating and feeling honest: Committing and punishing analog versus digital academic dishonesty behaviors in higher education. Interdisciplinary Journal of e-Skills and Life Long Learning, 12, 193-205. https://doi.org/10.28945/3629

Galloway, M.K. (2012). Cheating in advantaged high schools: Prevalence, justifications and possibilities for change. Ethics and Behaviour, 22(5), 378-399.

Harding, T.S., Carpenter, D.D., \& F inelli, C.J. (2004). Does academic dishonesty relate to unethical behaviour in professional practice? An exploratory study. Science and Engineering Ethics, 10, 311-324.

Heckler, N.C., \& Forde, D.R. (2015). The role of cultural values in plagiarism in higher education. Journal of Academic Ethics, 13(1), 61-75. https://doi.org/10.1007/s10805-0149221-3

Hu, G. \& Lei, J. (2012). Investigating Chinese university students' knowledge of and attitudes toward plagiarism from an integrated perspective. Language Learning, 62(3), 813-850. https://doi.org/10.1111/j.1467-9922.2011.00650.x

Ioannidou, M. (1997). Testing and life-long learning: Open-book and closed-book examination in a university course. Studies in Educational Evaluation, 23(2), 131-139.

John, L., Loewenstein, G., \& Rick, S. (2014). Cheating more for less: Upward social comparisons motivate the poorly compensated to cheat. Organizational Behavior and Human Decision Processes, 123, 101-109.

Johnson, C. (2006). Credentialism and the proliferation of fake degrees: The employer pretends to need a degree; the employee pretends to have one. Hofstra Labor and Employment Law Journal, 23(2), 269-343.

Jones, D.R.L. (2011). Academic dishonesty: Are more students cheating?. Business Communications Quarterly, 74, 141-150.

Josien, L., \& Broderick. B. (2013). Cheating in higher education: The case of multi-methods cheaters. Academy of Educational Leadership Journal, 17(2), 93-105.

Jurdi, H, Hage, H.S., \& Chow, P.H. (2011). Academic dishonesty in the Canadian classroom: Behaviour of a sample of university student. Canadian Jurnal of Higher Education, 41(3), $1-35$.

Lang, J.M. (2013). Cheating Lessons: Learning from Academic Dishonesty. Cambridge, MA: Harvard University Press.

Lin, C.H.S., \& Wen, L.Y.M. (2007). Academic dishonesty in higher education: A nationwide 
study in Taiwan. Higher Education, 54(1), 85-97.

Macfarlane, B., Zhang, J., \& Pun, A. (2014). Academic integrity: A review of the literature. Studies in Higher Education, 39(2), 339-358.

Mahmoud Poorian, Mohammad Javad Nekooei, \& Yusof Boon. (2013). Academic cheating in higher education. The effect of a student development approach: A study at Universiti Teknologi Malaysia. IOSR Journal of Research \& Method in Higher Education, 1(6), 4043.

McCabe, D.L. (2005). Cheating among college and university students: A North American perspective. International Journal for Educational Integrity, 1(1), 65-74.

Megat Ayob Megat Ariffin \& Abd Halim Ahmad. (2016). Kepentingan budaya integriti dan etika kerja dalam organisasi di Malaysia: Suatu tinjauan umum. Geografia-Malaysian Journal of Society and Space, 12(9), 138-149.

Mitchell, T., \& Carroll, J. (2008). Academic and research misconduct in the Ph.D: Issues for students and supervisors. Nurse Education Today, 28, 218-226

Nursiha Saidin \& Nurliyana Isa. (2013). Investigating academic dishonesty among language teacher trainees: The why and how of cheating. Procedia-Social and Behavioral Sciences, 90, 522-529.

Park, C. (2003). In other (people's) words: Plagiarism by university students: Literature and lessons. Assessment and Evaluation in Higher Education, 28(5), 471-488. https://doi.org/ $10.1080 / 02602930301677$

Pecorari, D., \& Petrić, B. (2014). Plagiarism in second-language writing. Language Teaching, 47(3), 269-302. https://doi.org/ 10.1017/S0261444814000056

Ramlan Mustapha. (2016). Ketidakjujuran akademik dalam kalangan mahasiswa muslim di Malaysia: Analisis perbandingan tahun 2014-2015. Jurnal Kurikulum \& Pengajaran Asia Pasifik, 40(1), 41-55.

Sarita, R.D. (2015). Academic cheating among students: Pressure of parents and teachers. International Journal of Applied Research, 1(10), 793-797.

Sureda-Negre, J., Comas-Forgas, R., \& Oliver-Trobat, M.F. (2015). Academic plagiarism among secondary and high school students: Differences in gender and procrastination. Comunicar, 22(44), 103-110. https://doi.org/10.3916/C44- 2015-11

Wayandiana Abdullah \& Rahimah Abdul Aziz. (2019). Integriti dan kesedaran polis orang asli terhadap rasuah. Dlm. Rahimah Abdul Aziz, Mohamad Fauzi Sukimi \& Nur Hafizah Yusoff (pnyt.), Malaysia: Pembangunan negara dan kerencaman isu sosial. Bangi: Penerbit Universiti Kebangsaan Malaysia.

Wilkinson, J. (2009). Staff and student perceptions of plagiarism and cheating. International Journal of Teaching and Learning in Higher Education, 20(2), 98-105.

Williams, K.M., Nathanson, C., \& Paulhus. D. (2010). Identifying and profiling scholastic cheaters: Their personality, cognitive ability and motivation. Journal of Experimental Psychology:Applied, 16, 293-307.

Williams, M.W.M., \& Willliams, M.N. (2012). Academic dishonesty, self-control and general criminality: Prospective and retrospective study of academic dishonesty in a New Zealand university. Ethics \& Behavior, 22(2), 89-112. 